\title{
Light in My Heart
}

\author{
Subhash Sharma* \\ Director, Indus Business Academy, India
}

Submission: August 10, 2017; Published: August 29, 2017

*Corresponding author: Subhash Sharma, Director, Indus Business Academy, India, Email: re_see@rediffmail.com

\section{Perspective}

Let noble thought come to us from all direction, Rigveda

Let noble thoughts Go from us in all directions, Quantum Rope

Big Bang led to creation of this world from Shunya in the form of light and clouds of waves and particles. Human beings arrived on the earth much later. They arose from the light and clouds of waves and particles. Thus, they are also product of creation from shunya and carry in their heart the sparks of the 'original light'. After their arrival, they were under wonderment and wondered at their own life and origin of the 'Original Light' as well as unfolding of Shunya in terms of matter, mind and consciousness.

Wonderment led to curiosity and later scientists started studying nature of Nature and nature of light. From their study they discovered that light is both wave and particle. Further, light led to an understanding of space and time. Newton concluded that space and time are Absolute. Einstein imagined moving with speed of light and from such an initial imagination came some interesting insights such as mass energy equivalence which found expression in famous equation, $\mathrm{e}=\mathrm{mc}^{2}$. Space and time are not Absolute concepts but are relativistic concepts, he concluded. Further, light is the ultimate limit in the universe. His formulations led to a major paradigm shift in human thinking with respect to light, space, time and related concepts. In my book, Quantum Rope (1999) I suggested a more generic equation $\mathrm{e}=\mathrm{m} \mathrm{c}^{\mathrm{n}}$ (Sharma 1999), wherein e represents energy, $\mathrm{m}$ represents matter and $\mathrm{c}$ represents consciousness and $\mathrm{n}$ can be $1,2,3, \ldots$ representing the expanding circles of consciousness. At the physical level, consciousness (c) is represented by light and thereby by speed of light (c). While Einstein's equation is at the physical level, $e=m c^{n}$ is at the generic level including all sheaths (koshas) of human existence and it represents equivalence of matter, energy and consciousness from the spiritual perspective. When consciousness expands like the oceanic waves, human beings reach higher levels of consciousness beyond the physical notions of space and time. In fact, $\mathrm{e}=\mathrm{m} \mathrm{c}^{\mathrm{n}}$ can be considered as a spiritual equation, as it suggests evolution towards nirvana (n) or 'zone of eternity' (represented by $\mathrm{n}$ in this equation). It also represents the 'ahm brahmasmi' state of consciousness. In this equation, $\mathrm{m}, \mathrm{e}, \mathrm{c}, \mathrm{n}$ also represent gross, subtle, supra-subtle and astral states of mind and these are broadly in consonance with waking, dream, deep sleep and trance (Samadhi) states of consciousness. In the equation, e $=m c^{n}$, we find an interconnectivity among various states of consciousness.

Einstein imagined moving with 'speed of light' and gave us his famous ideas and theories. Once I took liberty of poetic imagination and this led to a poem under the title, 'Velocity of Light' that was published in my book, Quantum Rope (1999, p.13). In Physics, light is considered a scalar quantity, however, when viewed from spiritual perspective, light guides and provides a direction, hence, it can also be considered vector quantity. This provides the reason for title of the poem as 'Velocity of light' instead of 'Speed of light'. In this poem Einstein's idea of twin paradox is also captured. The poem is as follows:

You said long time and no see

I had met you tomorrow near the sea

You said we have met somewhere

I had met you in your future

Because I was travelling with velocity of light

And you were travelling with velocity of kite

I went out on a tour of galaxies

My classmates were still hiring taxies

When I returned home, I was in a younger mould

My classmates had grown very very old

Because I was travelling with velocity of light

And they were travelling with velocity of kite 
(Velocity of light, quantum rope: science, mysticism and management, Subhash Sharma, 1999, p.13)

When you light a lamp or candle or switch on light, the darkness is removed. Thus light gives us a lesson that there is no need to Fight. In fact there are three types of individuals viz. those who use 'Fight' approach, those who use 'Flight' (Moving to another space or place/ Flight of Imagination) approach and those who use 'Light' approach to achieve success. Believers in Fight approach tend to give a negative meaning to Flight approach as they equate it with escapism. However, 'Flight' approach can also be a creative as example of Sri Krishna shows us. He took 'Flight' approach (left Mathura to create Dwarika) and used it in a creative way to create a new city and a new perspective. Further he also took the Light approach to enlighten the whole world through his new insights as is evident from Gita. When individuals take the Light approach, they act like the lamp or candle, spreading their ideas and wisdom to remove darkness. Buddha said, become a lamp and remove the darkness. In fact it is up to an individual to follow any of these paths. His/her choice depends on his/her awareness, awakening and self evolution stage. Through light of knowledge, wisdom and consciousness, ignorance is removed. Light is a symbol of noble thoughts. By lighting the lamp of knowledge ('knowledge lamp'), we spread the noble thoughts in all directions.

As I reflected and meditated on the deeper meaning of LIGHT in terms of five letters of its spelling, it led me to a new meaning of LIGHT in terms of Light (L), Infinity (I), God (G), Harmony (H), Truth (T). This LIGHT led me to the following LIGHT Equation:

$$
\mathrm{L}=\mathrm{I}=\mathrm{G}=\mathrm{H}=\mathrm{T}
$$

Light $(\mathrm{L})=\operatorname{Infinity}(\mathrm{I})=\operatorname{God}(\mathrm{G})=\operatorname{Harmony}(\mathrm{H})=\operatorname{Truth}(\mathrm{T})$

Thus, Light is Infinity, Light is God, Light is Harmony and Light is Truth

This interpretation of LIGHT provides us a new vision and this vision can be expressed in terms of following four principles:

Light is Infinity, Infinity is Light ( $\mathrm{L}=\mathrm{I})$

Light is God, God is Light $(\mathrm{L}=\mathrm{G})$

Light is Harmony, Harmony is Light $(\mathrm{L}=\mathrm{H})$

Light is Truth, Truth is Light $(\mathrm{L}=\mathrm{T})$

It may be observed that Gandhi's famous quote, God is Truth and Truth is $\operatorname{God}(\mathrm{G}=\mathrm{T})$ is a derivative of these principles. Further all religions refer to these principles in one form or other. In fact this interpretation of LIGHT provides us the Oneness vision of all religions and spiritual traditions.

I may indicate that the 'LIGHT Vision' suggested here is essentially a realization of 'Light in our hearts'. In 1993, I wrote a song titled as 'Light in my Heart' and it was published in my book, Creation from Shunya. This song was adopted in 1996, by first batch students of WISDOM (Women's Institute for Studies in Development Oriented Management), Banasthali University, Banasthali, Rajasthan, as 'Wisdom song'. This song can also be considered as a 'song of light'. Some lines of this song are as follows:

\section{There is light in my heart}

It is there from the start

Its mystery you want to know

It says hello hello ...

It give me a peep

Into things that are deep

It has a beautiful glow

It says hello hello ...

It shows silver lines

Bending space and time

In nature's beauty show

It says hello hello ...

This light is divine

It makes us fine

Its flow is very slow

It says hello hello ....

\section{(Light in my heart, creation from Shunya, Subhash Sharma, 1993, p. 33)}

Let this 'LIGHT Vision' in the form of 'LIGHT in our hearts', spread in all directions for the benefit of all. This vision represents the essence of the 'Wisdom, Consciousness and Light of India' that many across the world are seeking to create a new vision for the world based on a consciousness shift from fight to light - from lower levels of consciousness to higher levels of consciousness. Realization of 'Light in My Heart' has the potential of transforming the world in to Pragyasthan(A Place of Wisdom), where Science (Scientific temper and scientific approach, Rationalistic worldview), Heart (Heartistic approach, Heart values, Human values) and Spirituality (Spiritual temperament and spiritual approach) find a new integration for the benefit of the whole world. In modern society, Head is given primacy over Heart even though Head owes its vitality to Heart because Heart is the source of blood supply to Head. This implies that science and rationality are incomplete without human values and spirituality. This realization dawns when we realize 'Light in our hearts'. 


\section{Light in my heart as a step towards higher evolution}

Darwin to divinity: Above discussion takes us towards a model of "Arrival of Human Beings and Self evolution". In the beginning of this article, we mentioned about creation of this world from the 'original light' and clouds of waves and particles that took shape in the form of Panchmahabhutas (Five elements). 'Natural interactions' along with various 'permutations and combinations' among five elements combined with natural 'quantum churning' arising from natural interactions, lead to creation of life in various forms. This led to 'arrival of human beings' from the 'clouds'. This perspective based on 'creation from shunya' provides us a new approach to creation and evolution of life including human beings. Original Light is embedded in the heart of every human being and this provides the basis for higher evolution of human being towards realization of this light within. Darwin dealt with evolution through natural selection at the Biological level. It may be indicated that at biological level, human beings are no different from animals and are particularly very close to certain species. However, they differ from animals because of more developed neuron structures in human mind. Sri Aurobindo was concerned with human evolution at the mind and consciousness level. Dasavatara theory of evolution represents an integral approach to evolution wherein we find an integration of the matter, mind and consciousness (mmc) approaches to human evolution. This integration suggests that 'Shunya Unfolding' (SU)' has been taking place in a natural way in terms of matter (gross level), mind (subtle level) and consciousness (supra-subtle level)) and this 'natural unfolding' is represented by Body, Heart and Spirit (BHS). As we transcend Body (gross), Heart (subtle) and Spirit (supra-subtle) levels, we realize our cosmic/ divine/astral nature that has been referred to as 'aham brahmasmi'. Thus, we have following perspectives on human evolution:

a. Creation from Shunya: Arrival of life from the clouds of waves and particles

b. Darwin's theory of evolution: Biological perspective on evolution

c. Aurobindo's perspective of mind evolution

d. Dasavatara 'theory'/ view of evolution

e. 'Aham brahmasmi'/ Divinity/ Divine being view of evolution

'Cloud theory' of evolution suggests creation of life from the clouds of waves and particles, happens as a result of (i) natural interactions, (ii) permutations \& combinations (iii) quantum churning. In contrast, Darwin's biological evolution is result of nature's selection and biological fitness. Higher evolution among human beings is result of self effort and thereby self selection on the part of human beings. In consonance with the above, there are various stages of human evolution viz. shunya stage, biological stage, heart-mind awakening stage, consciousness enlightenment stage and cosmic being stage. While some persons remain at the biological stage, hence, their behaviour is driven by Biological (B) factors and they remain at Darwinian level of existence and believe in 'survival of the fittest to eliminate the rest'. Some move to next stage represented Heart's Awakening (HA) and by Human values, heartfulness and heartistic approach to life and human existence, some move further to the next stage represented by Spiritual (S) values and spiritual temperament and a few reach the cosmic being level as they have inner desire for 'cosmic realization' of reaching Harmonic Oneness (HO) stage represented by 'aham brahmasmi'. YOGA, when defined as "Yearning for Oneness and Gaining Advancement" (Sharma 1996, in 'Western Windows Eastern Doors'), helps our self evolution towards Harmonic Oneness (HO). According to Swami Vivekananda, every human being is potentially divine and aim of human, beings is to manifest this divinity within. Thus, human journey is a journey from 'Shunya Unfolding' (SU) through Biological (B), Heartfulness (H), Spiritual (S) stages and finally reaching Harmonic Oneness (HO) stage. In essence this represents evolution from Biological (B) being to Human $(\mathrm{H})$ being ('being human'), Spiritual (S) and Cosmic being representing Harmonic Oneness (HO) with everything around us. These stages represent the expanding circles of human consciousness from biological state to cosmic/ divine being state. Hence, we refer this model as 'Darwin to Divinity' and this four circles model of human evolution is presented in Figure 1.

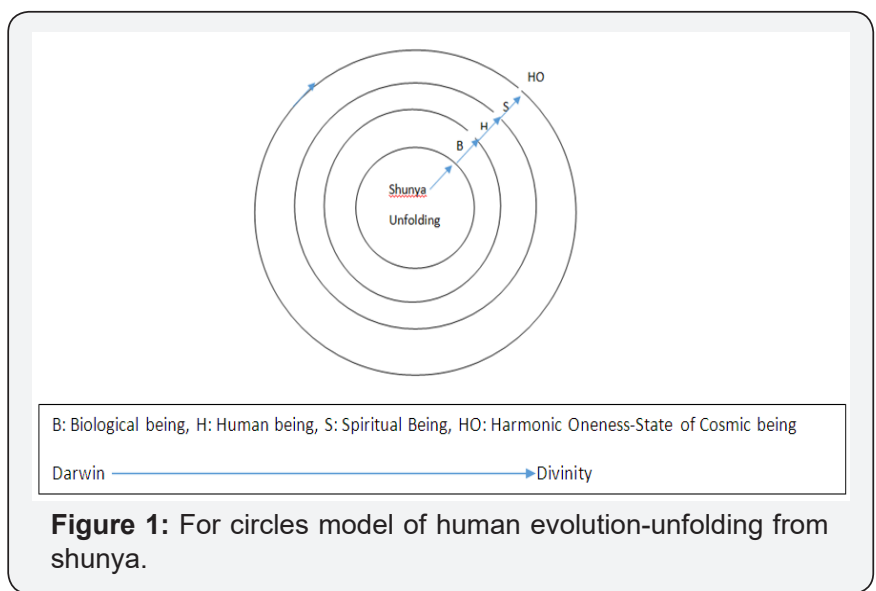

Above presented model of human evolution is also captured in the following poem titled as 'I Am a New Religion' (Shunya Poems, Subhash Sharma, 2010, p. 43):

I am a new religion, Higher than every religion,

A religion of being, being a human being,

Being a higher being, being a cosmic being,

I am a new science, Higher than every science,

A science of being, being a human being,

Being a higher being, being a cosmic being, 
I am a new ism, Higher than every ism,

An ism of being, being a human being,

Being a higher being, being a cosmic being,

I am a new identity, Higher than every identity,

An identity of being, being a human being,

Being a higher being, being a cosmic being,

I am a new consciousness, a consciousness of being,

Being a higher being, being a cosmic being.

(I am a New Religion, Shunya Poems, Subhash Sharma, 2010, p. 43)

It may be indicated that this poem also traces the journey of human society since 'shunya unfolding' and the arrival of human beings on earth. This journey is a journey from Religion (s) to Science to Ideologies in the form of many Isms that originated in 19th and 20th century with their intellectual foundations in conflict and violence and to current focus on Identities (e.g. national identity, regional identity etc.). It also suggests future evolution towards a new consciousness of being a cosmic being. Realizing 'Light in our hearts' is a step in this direction.

\section{Conclusion}

In conclusion it may also be mentioned that the New Consciousness originating from the realization of 'Light in my heart' also provides us a message of equality and dignity as same quantum of light is flowing through every human being. Once we realize Light in our hearts we are ready to take steps and quantum jumps towards higher evolution taking us beyond biological/ Darwinian evolution. This will create a paradigm shift from 'survival of the fittest to leave behind the rest' to 'arrival of the best to lead the rest'. This is also the essential message of VYOMA: Vedanta, Yoga, Meditation and Awakening for all.

\section{Your next submission with Juniper Publishers will reach you the below assets}

- Quality Editorial service

- Swift Peer Review

- Reprints availability

- E-prints Service

- Manuscript Podcast for convenient understanding

- Global attainment for your research

- Manuscript accessibility in different formats ( Pdf, E-pub, Full Text, Audio)

- Unceasing customer service

Track the below URL for one-step submission https://juniperpublishers.com/online-submission.php 